(C) 2015 IEEE. Personal use of this material is permitted. Permission from IEEE must be obtained for all other uses, in any current or future media, including reprinting/republishing this material for advertising or promotional purposes, creating new collective works, for resale or redistribution to servers or lists, or reuse of any copyrighted component of this work in other works. 


\section{Power-to-Gas Potential Assessment of Portugal Under Special Consideration of LCOE}

\author{
Fabian Heymann \\ CPES and Institute of Geology and Geography \\ INESC TEC and Julius-Maximilians-University of Wurzburg \\ Wurzburg, Germany \\ fheymann@inescporto.pt
}

\author{
Ricardo Bessa \\ Centre for Power and Energy Systems (CPES) \\ INESC TEC \\ Porto, Portugal \\ ricardo.j.bessa@inesctec.pt
}

\begin{abstract}
Power-to-Gas can contribute with valuable balancing power and seasonal storage capacity to future power systems. In Portugal, forecasts for $\mathbf{2 0 2 0}$ show significant excess of renewable energy generation that can be transformed by power-to-gas technology and fed into the natural gas infrastructure. This work suggests an innovative approach to assess future power-togas integration potentials at the national level, focusing on wind power. Following a geographical distance analysis, a first economical estimation of future energy transformation costs is made with the help of Levelized Costs of Energy (LCOE).
\end{abstract}

Index Terms-- Geographic information system, Renewable energy sources, Energy storage, Wind energy integration.

\section{INTRODUCTION}

With the variable patterns of renewable energy sources (RES) and possibility of energy surplus, energy storage technologies are becoming crucial assets within modern power systems. Recent studies reveal that Portugal will yield power production excess in a range of $800-1200 \mathrm{GWh}$ annually by 2020 [1]. Given the actual conversion efficiencies [2], at least $500000 \mathrm{MWh}$ are storable annually. This way, Renewable Power Methane or Synthetic Natural Gas (SNG) can help storing power and supply carbon-free energy to the transport and heating sector, but also reduce political tensions and contribute to the energy infrastructure while stabilizing the electrical grid [1]. As Portugal is depending on imported hydrocarbons by almost 100\% [3], SNG could also help to diversify the natural gas supply and improve security of energy supply. Gas networks and salt caverns are the largest gas storage facilities, providing mature and available technology and can incorporate future powerto-gas products [4], [5]. With its existing network of natural gas grids, already operating salt caverns in Carriço and forecasted excess of renewable power generation, Portugal can be seen as a predestinated country to implement future power-to-gas technology.

This paper is organized as follows: Section II consists of a brief description of the fundamental pillars of the assessment methodology. Ongoing the presentation and discussion of scenarios built and technological features used in the economic modeling process is followed by the estimation of the natural gas storage potentials in the parts III and IV. Grounded on research and data collection of the previous sections, the fifth section concentrates on the geographical component of power-to-gas potential assessment, integrating land-use restrictions into the evaluation process and enhancing the assessment to a spatial dimension while combining Geographic Information Systems (GIS) with a diverse set of ecological and economic criteria. Finally, the computed results are presented within the sixth section both in a numerical and visual, spatially distributed way. Drawn conclusions and open questions are addressed as a closing part in section VII.

Considering the existent state of the art [6], [7], the proposed method is an original contribution since it provides a new approach to study power-to-gas integration feasibility from the geographical standpoint, enhancing GIS-based, geospatial analysis with economic evaluation criteria (LCOE).

\section{ASSESMENT Methodology}

The methodology described in this paper consists of the following steps:

\section{A. Literature Review}

At the beginning, information was retrieved on the way existing storage utilities could accommodate SNG, using available power excess projections and literature of the relevant geological formations in Portugal. Gas storage utilities being considered are the natural gas grid as well as existing and potential future underground salt caverns on continental Portugal. Furthermore, the literature review untapped information of existing power-to-gas pilot plants revealing data on technological and economic characteristics and estimations on further techno-economic development.

\section{B. Geostatistical Analysis of Wind Power Plants and Natural} Gas Infrastructure

As a second step, wind power plant locations in Portugal (WPP) were evaluated with geospatial analysis conducted 
with the software packages of QGIS 2.6 and ArcGIS 10.1 in order to receive information on the distance patterns between WPP and the storage utilities and evaluate future power-to-gas plant integration into the natural gas grid infrastructure. At this point, a toolbox was created that was able to extract automatically relevant georeferenced information and computed the requested attribute layers such as shapefiles of WPP distances to storage infrastructure. The same, sensitive or protected habitat areas were excluded for future natural gas storages (salt caverns) in order to integrate ecological and land-use restrictions for future power-to-gas site analysis.

\section{Techno-Economic Assesment of Power-to-Gas Integration with $L C O E$}

Based on the previous steps, the future cost of power-togas was assessed on scenario basis. The Levelized Costs of Energy (LCOE) methodology is employed as economic evaluation tool in order to estimate the cost of SNG or derived electricity. This way, a first estimation of the impact of power-to-gas technology on cost structures within the electricity and gas sector could be obtained. Further, it became possible to compare power-to-gas to other existing technologies. In order to approach the uncertainty associated to the future development, different scenarios were employed with varying model parameters (compare Table I). These scenarios used actual figures and a range of estimations referring to technological development and the overall market design.

\section{Scenario Building And TeChnolgical Setting}

The three different scenarios built tried to reproduce possible development pathways integrating technological improvements and policy adaptations.

\begin{tabular}{ll}
\multicolumn{1}{c}{ TABLE I. } & \multicolumn{1}{c}{ TECHNOLOGICAL AND ECONOMIC } \\
PARAMTERS
\end{tabular}

Those scenarios thus differ in their specific capital costs, the prices of electricity as process input and the overall conversion efficiencies, trying to consider existing spans of technological efficiencies and cost structures and the expectations of their future development as provided by the literature [2], [5], [7], [8].

While in the standard scenario, a conversion efficiency of $36 \%$ to power and a $60 \%$ conversion efficiency to SNG with a total capital costs of $2,000 € / \mathrm{kW}$ and electricity costs at $0.04 € / \mathrm{kWh}$ was selected, these values were decreased to
$1,500 € / \mathrm{kW}$ and $0.02 € / \mathrm{kWh}$ respectively $1,000 € / \mathrm{kW}$ and $0 € / \mathrm{kWh}$ in the most optimistic case. Meanwhile, process efficiencies were increased to $45 \%$ and $50 \%$. All calculations assumed an overall conversion capacity of the power-to-gas converter of 5MW with operational costs representing $3 \%$ of the capital costs and an interest rate of $7.5 \%$ over the total lifetime of the plant (20years) [8].

The conversion technology taken into account is a PEM hydrolyzer, whose high efficiency was set to $70 \%$ and is decreased to $60 \%$ in the ongoing methanation process. Then, the efficiency chain was combined with a typical CHPefficiency of $60 \%$ for re-conversion to electricity, according to $[2,8]$. At this point, it is necessary to underline that the methanation step, thus the step of recombining hydrogen and $\mathrm{CO} 2$ to $\mathrm{SNG}$, was modeled as a closed cycle, where a carbon dioxide source is available within the conversion process. An additional extraction of $\mathrm{CO} 2$ from the atmosphere would have on the other side necessarily negative implications on the total conversion efficiency as the self-consume of energy of the conversion process rises [9].

\section{Natural Gas Storage Potential ASSESSMENT AND LAND-USE RESTRICTIONS}

Firstly, information on natural gas storage potential was evaluated. Regional geology studies delivered data on salt geology and diapirism occurrence, which were further regarded as potential sinks for gas storage in salt caverns [10 - 13]. Regarding future gas storage potentials, the Algarve and Lusitanian basins were of major research interest due to the occurrence of salt formations and their potential suitability for salt caverns. Their main geological features and relevant key information regarding their potential to store natural gas are shown in Table II.

TABLE II. Underground CAVERN Storage Potential IN PORTUGAL

\begin{tabular}{|l|c|c|}
\hline \multirow{2}{*}{ Features } & \multicolumn{2}{|c|}{ Salt formations/ outcropping salt diapirs } \\
\cline { 2 - 3 } & Algarve Basin $^{\boldsymbol{a}}$ & Lusitanian Basin $^{b}$ \\
\hline Extension $\left[\mathrm{km}^{2}\right]$ & 2600 & 23000 \\
\hline Thickness [m] & \multicolumn{2}{|c|}{ Max. $5000-6000 \mathrm{~m}$} \\
\hline $\begin{array}{l}\text { Thickness of Salt } \\
\text { formation [m] }\end{array}$ & Max. 1500 & $400-2000$ \\
\hline Reference purity [\%] & N/A & $85($ Carriço) \\
\hline $\begin{array}{l}\text { Theoretical potential } \\
\text { [bcm] }\end{array}$ & 1.95 & 18.60 \\
\hline $\begin{array}{l}\text { Available potential } \\
{[\mathrm{bcm}]}\end{array}$ & - & 1.0 \\
\hline
\end{tabular}

The calculations were made assuming that one cavern will be feasible per $\mathrm{km}^{2}$ surface salt and disregarding homogeneities both laterally and vertically within the salt structures. As a reference cavern (pressure, depth, storable volume, and salt content in layers) served the documented properties of a Carriço salt cavern, which is located in the northern branch of Leiria District and represents the biggest salt-bond gas storage on the Iberian Peninsula [16]. Being in operation since 2005, it provides a volume of $0.2 \mathrm{bcm}$ of working gas to the Portuguese national gas storage, but represents only a negligible quantity of the total European gas 
storage potential of $9.06 \mathrm{bcm}$ within gas cavern infrastructures [16 - 18].

Regarding future storability, two potential hierarchies were discriminated. While the theoretical potential $\left(\mathrm{TP}_{\mathrm{NGS}}\right)$ represents the total amount of natural gas storable within the Portuguese natural gas grid and existing as well as future potential salt caverns, the available storage potential of natural gas storage $\left(\mathrm{AP}_{\mathrm{NGS}}\right)$ was defined in accordance to the criteria framework established by [13] and diminishes the total quantity computed in the theoretical potential with the help of land-use restrictions. These restrictions are the exclusion of ecologically sensitive areas and buffer areas providing pre-defined distances to settlements, roads and other infrastructure means. The relevant data sets, namely Corine Land Cover 2006 raster data with a resolution of 100 x 100m (enhanced version of 2010) and habitat information on protected areas from Natura 2000 data were retrieved from the website of the European Environment Agency (EEA) [19].

As a result of this, the search for future access points of potential power-to-gas plants with vicinity to the natural gas infrastructure such as the national gas grid and potential saltbond storage caverns were defined by excluding sensitive and prohibited areas in accordance to the developed framework in [13]. It is important to underline that the computed salt cavern locations and their storable quantities do represent estimations without numerical sharpness for operational utilization and primarily express the upper boundary of the available resources without taking into account site-specific conditions of the geological underground or land restrictions of legal planning authorities, e.g. municipalities or regional development agencies. Their mathematical formulation is listed below:

- Theoretical potential

$$
\mathrm{TP}_{\mathrm{NGS}}=N G G+S C_{e x}+S C_{p o t, t h}
$$

- Available potential

$$
\mathrm{AP}_{\mathrm{NGS}}=N G G+S C_{e x}+S C_{p o t, a v}
$$

The formulas above computed the volume of natural gas storage on continental Portugal (in billion cubic meters - bcm). These two calculations do consider the storage volume of the Portuguese Natural Gas Grid (NGG), the gas volume storable in existing salt caverns $\left(\mathrm{SC}_{\mathrm{ex}}\right)$ and potential further salt caverns $\left(\mathrm{SC}_{\mathrm{th} \text {,pot }}\right)$ in reported outcrops of salt layers in the estimation of the theoretical storage potential. The available potential estimation just differs to the first equation by replacing the total amount of gas theoretically storable in existing salt domes/ layers $\left(\mathrm{SC}_{\mathrm{pot}, \mathrm{th}}\right)$ by $\mathrm{SC}_{\mathrm{pot}, \mathrm{av}}$, which represents the storage potential considering land-use restrictions as defined in [13]. In other words, the latter is representing the ecologically and technically feasible amount of natural gas storable in geological salt structures. In other words, the calculation of the available potential uses the same values as found in the calculation of the theoretical potential, but including the available potential of further salt caverns estimated, diminishing the storage potential of feasible salt cavern standpoints with a framework of land-use restrictions and WPP vicinity.

The total theoretical storage potential of natural gas in continental Portugal within the existing infrastructures and excluding Liquefied Petroleum Gas Terminals (LPG) was determined to yield approximately $21 \mathrm{bcm}$. This value can be regarded as the upper boundary, which so far did not include any techno-economic or ecological (land-use) restrictions. Decreasing the utilizable amount with the application of the established framework of [13], the available storage potential would yield $1.24 \mathrm{bcm}$. The yearly amount of $0.24 \mathrm{bcm}$ [18] of natural gas stored within of the existing natural gas grid in continental Portugal is assumed as the fixed available storable amount of natural gas or SNG.

\section{GIS-BASED DISTANCE ANALYSIS AND LCOE PATTERNS}

Using the LCOE methodology [20], this work provides as well an economic assessment on the integration (e.g. connection) of power-to-gas utilities into the existing networks (electricity or natural gas). Focusing on the connection costs of power-to-gas integration in Portugal, distance as the main driver of grid extension costs was the criteria of interest. The LCOE formula with its standard parameters such as product lifetime $(\mathrm{t})$, investment $\left(\mathrm{I}_{0}\right)$ and operational $\left(\mathrm{A}_{\mathrm{t}}\right)$ costs and the produced quantity of electricity $\left(\mathrm{M}_{\mathrm{t}}\right)$ was enhanced with a cost function of grid extension. This function (EC) describes the impact of the distance between potential gas storages and WPP to the costs of future power-to-gas products. The complete equation is shown below (Eq. III).

$$
L C O E=\frac{I_{0}+\mathrm{EC}_{0}+\sum_{t=1}^{n} \frac{A(t)}{(1+i)^{t}}}{\sum_{t=1}^{n} \frac{M_{t, e l}}{(1+t)^{t}}}
$$

Within the nature of LCOE calculations, it is clear that the computed cost structures do not represent individual and sitespecific cost patterns of power plant locations. Moreover, the LCOE methodology allows this way to estimate future competitiveness of power-to-gas technology and provides an assessment tool for its potential integration into the energy sector. The simulation itself considers the pipeline or natural gas grid extension costs (EC) as a linear product of the direct geographical distance (GD) and construction costs per $\mathrm{km}$ (CC). In this simplified approach, further cost-influencing factors such as labor, additional auxiliary materials (gas densifier stations, transformer stations, etc.) or orographic effects were neglected. It was found that under the defined conditions, appropriate electrical grid extension costs per $\mathrm{km}$ are in Portugal with $200,000 € / \mathrm{km}$ about four times lower than the construction costs for gas pipelines and were therefore considered as only extension option [21] - [23].

In the GIS-based analysis, the distance between potential storage utilities and WPP in Portugal was computed. An ArcGIS toolbox was created in order to automate the evaluation process and analyze the distance patterns. The 
toolbox is based on the spatially referenced data-sets of potential storage means (natural gas infrastructure and salt layers) and the locations of wind power plants. The georeferenced wind power plant sites and information regarding their installed capacity were retrieved from the project Endogenous Energies of Portugal $\left(\mathrm{e}^{2} \mathrm{p}\right)$ from INEGI and APREN [24]. The developed algorithm of the created toolbox is shown in Figure 1. The different techno-economic scenarios were considered by running the process with the defined sets of values as in Table 1. In order to automatize the routines, the toolbox was iteratively run and thus computed the distance patterns from the natural gas storage devices for each scenario. As a result, a map shows the distance of each pixel to the defined storage locations such as the national gas grid or existing and potential salt caverns within the surveyed area (Figure 2). Then, with the help of raster calculating routines, the adopted LCOE formula was integrated into a GIS tool which determined the final LCOE values and their spatial distribution on Portuguese (continental) territory. The methodology does not take into account geomorphological barriers and uses the direct air distance between the points of interest.

Finally, the resulting layer of distance patterns was intersected with the existing wind power plant locations and that way the distances between these power plants and the natural gas storages could be extracted to another layer. This layer was evaluated statistically in order to assess the relation between geographical distance between the WPP and storage devices and future connectable power.

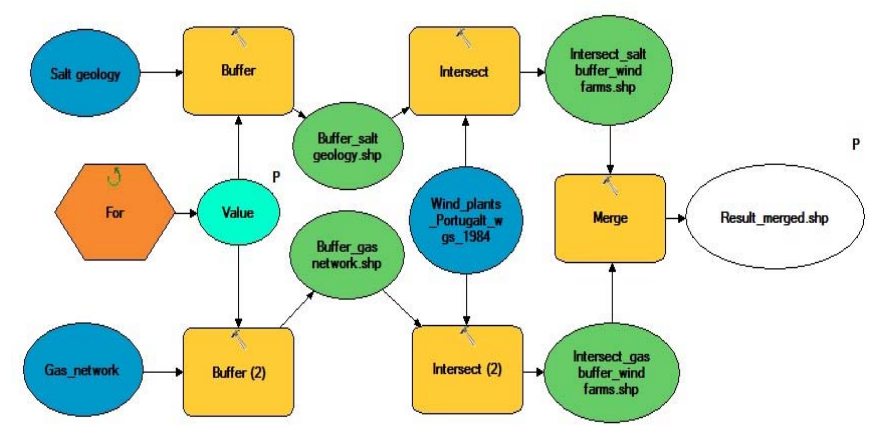

Figure 1. Developed ArcGIS-toolbox to compute distance patterns between WPP and gas storage utilities

\section{RESULTS}

The distance analysis displayed a range of $0-62 \mathrm{~km}$ at maximum between a WPP and potential natural gas storage utilities. Figure 2 displays the spatial relationship between the LCOE cost estimations and the distance between WPP and natural gas storages. The LCOE is colored white inside the Portuguese mainland for most attractive power-to-gas plant positions and dark blue in regions with high difficulties for power-to-gas employment due to long distances between WPP and gas storage infrastructures. It is clearly visible that the costs for power-to-gas products decrease towards the Region of Alentejo and the Nord, away from geological salt structures (and thus potential salt caverns) and the national natural gas grid. Furthermore it becomes visible that only few wind parks are in close distance to the national gas grid infrastructure.

Considering the distance of WPP to potential storage utilities, the outcomes show that within the radius of $3 \mathrm{~km}$ already one third of the installed wind power capacity could be attached to a potential natural gas storage device. Almost $60 \%$ of installed wind power capacity could be interconnected to existing or future potential natural gas storage within the range of $5 \mathrm{~km}$. Pilot projects for power-togas technology with direct njection to the national gas grid infrastructure would be most feasible in the northern part of Lisbon District, where a high density of closely connectable wind power plants meets existing gas pipeline networks.

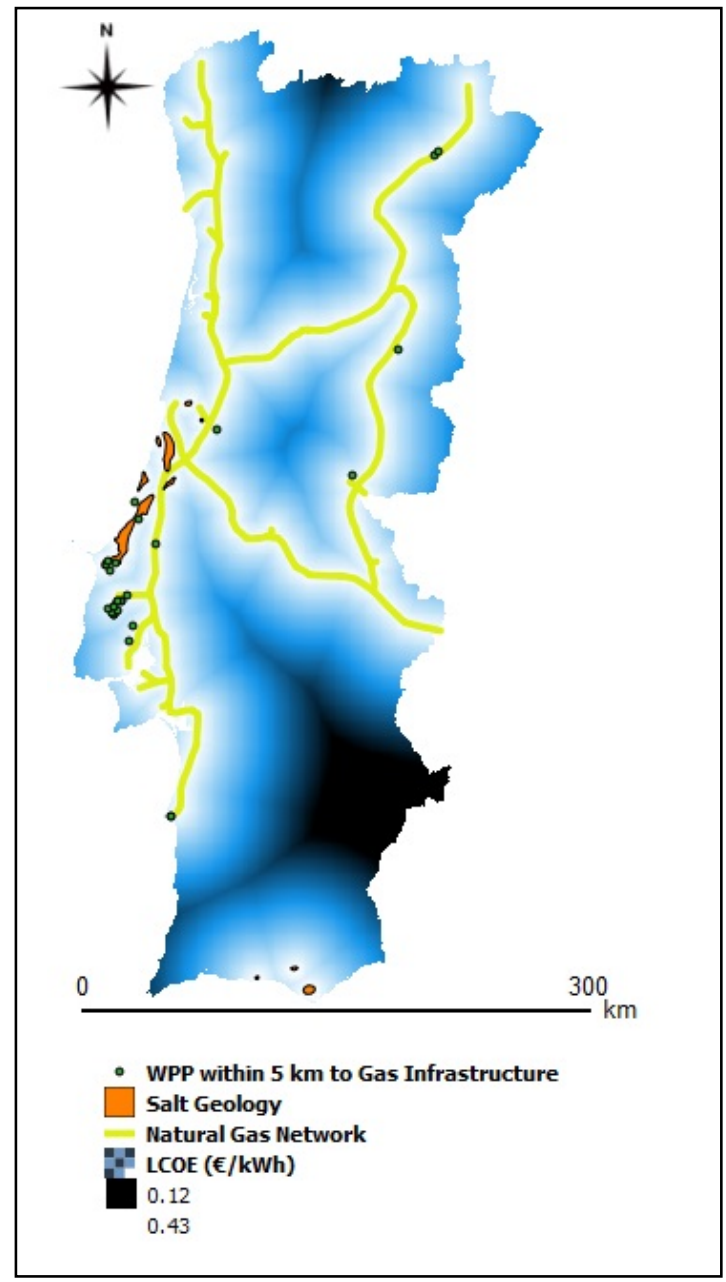

Figure 2. Computed LCOE patterns as a function of distance between WPP and gas storage utilities in Portugal

Taking into account the anteriorly defined scenarios, the LCOE for power-to-gas-to power (with re-conversion to electricity) would yield $0.26-0.43 € / \mathrm{kWh}$ at base scenario conditions. Their range corresponds to the varying extension costs due to the computed distance patterns. With ongoing maturation of the technology, power-to-gas could deliver electrical energy for $0.08-0.20 € / \mathrm{kWh}$ on continental Portugal, which would be still two to five times the averaged spot market price of electricity over the past five years [25]. 
Considering SNG as final product of the conversion process, LCOE could be decreased to maximal $0.05-0.1 € / \mathrm{kWh}$ and provide a considerably closer range to the domestic gas prices within the last regulation period of $0.07 € / \mathrm{kWh}$ [26], which is a major contribution of the higher conversion efficiencies under these conditions.

\section{CONCLUSIONS}

Under the economic point of view, it can be concluded that also under consideration of the most optimistic scenarios, power-to-gas technology will still face strong barriers in Portugal in the near future, which could be lowered only with significant technological improvements (lower prices of power-to-gas technology, higher conversion efficiencies), rising gas prices or system designs allowing market entrance for capacity mechanisms. However, the high quantity of installed wind power capacity within close distance $(<5 \mathrm{~km})$ to potential gas storage devices underlines the potential role power-to-gas could play in the energy system of the future. Methodologically, the GIS-based potential assessment showed innovative design and provided a useful toolbox available for future decision makers within that field. This approach allows a simple and automatized way to compute the potential of power-to-gas technology on a spatial basis, while incorporating diverse ecological restrictions and LCOE as major economic evaluation criteria. The further integration of spatial information of carbon dioxide emitting power plants or industrial sites would be advantageous to complement the assessment and close the chemical cycle of the methanation step, although information retrieval on national level is a difficult task.

\section{ACKNOWLEDGMENT}

This work is financed by the FCT - Fundação para a Ciência e a Tecnologia (Portuguese Foundation for Science and Technology) within project UID/EEA/50014/2013. Special thanks goes to Rúben Soares, as his patience and constant support shaped this work on the content dimension.

\section{REFERENCES}

[1] C.B. Mateus, A. Estanqueiro, "Regulation of the wind power production: contribution of the electric vehicles and other energy storage systems", 11th International Workshop on Large-Scale Integration of Wind Power into Power Systems as well as on Transmission Networks for Offshore Power Plants, Lisbon 13-15 November, 2012, 4p. Available

http://repositorio.lneg.pt/bitstream/10400.9/1885/1/Paper_WIW12052_CMateus.pdf

[2] M. Sterner, "Bioenergy and renewable power methane in integrated $100 \%$ renewable energy systems. Limiting global warming by transforming energy systems", Fraunhofer: Erneuerbare Energien und Energieeffizienz Band 14, Kassel University press, 2009.

[3] International Energy Agency,"Oil and Gas Emergency Policy Portugal", updated chapter in Oil Supply Security: Emergency Response of IEA Countries, 2011, pp. 1-18.

[4] Cerbe, G., "Grundlagen der Gastechnik. Gasbeschaffung Gasverteilung -Gasverwendung" revised $7^{\text {th }}$ version, German Technical and Scientific Association for Gas and Water, Munich, 2008, 516p.

[5] J. Kepplinger, F. Crotogino, S. Donadei, "Present Trends in Compressed Air Energy and Hydrogen Storage in Germany", SMRI Technical Conference, 3-4 October, York (United Kingdom), 2011.
[6] L. Castro-Santos, G. Prado Garcia, A. Estanqueiro, P. Justino, "The Levelized Cost of Energy (LCOE) of wave energy using GIS based analysis: The case study of Portugal", International Journal of Electrical Power \& Energy Systems, Volume 65, 21-25, 2015.

[7] G. Lukas, P. Schulze, J.Holstein, "Systems analyses Power to Gas: A technology review" Final Report, DNV KEMA Energy \& Sustainability, Groningen, 2013.

[8] C. Baumann, R. Schuster, A. Moser, "Economic potential of power-togas energy storages", 10th International Conference on the European Energy Market (EEM), Stockholm, 27-31 May, 2013.

[9] M. Specht et al., "Speicherung von Bioenergie und erneuerbaren Strom im Erdgasnetz", Erdöl, Erdgas \&Kohle, Volume 126, Hamburg, 2010.

[10] H. Mathias, et al., "Salt Tectonics in the Western Gulf of Cadiz (SW Iberia)", $2^{\text {nd }}$ Central \& North Atlantic Conjugate Margins Conference, Lisbon, Volume III, pp. 176-180, 2010.

[11] L.M. Pinheiro, R.C.L. Wilson, R.Pena dos Reis, R.B.Withmarsh, A. Ribeiro, "The Western Iberian Margin: A Geophysical and Geological Overview", Proceedings of the Ocean Drilling Program - Scientific Results, Vol. 149, pp. 1-14, 1996.

[12] N. Pereira, J.F., Carneiro, A. Araújo, M. Bezzeghoud, J.Borges, "Seismic and structural geology constraints to the selection of $\mathrm{CO} 2$ storage sites - The case of the onshore Lusitanian basin, Portugal", Journal of Applied Geophysics 102, pp. 21 - 38, 2014.

[13] P. D. V. Correia Nunes, "Potencial de Armazenamento Subterrâneo em Cavidades Salinas de Gás Natural em Portugal”, M.Sc. Dissertation , Instituo Superior Técnico, Lisbon, December 2010. Available https://fenix.tecnico.ulisboa.pt/downloadFile/395142226817/Armazena mento_Subterr\%C3\%A2neo_de_G\%C3\%A1s_Natural.pdf

[14] F.C. Lopes, P.P. Cunha, B. Le Gall, "Cenozoic seismic stratigraphy and tectonic evolution of the Algarve margin (offshore Portugal, southwestern Iberian Peninsula)", Marine Geology 231, pp. 1 - 36, 2006

[15] R.C.L. Wilson, "Mesozoic Develoment of the Lusitanian Basin, Portugal", Revista de la Sociedad Geológica de España 1 (3-4), 1988.

[16] Solution Mining Research Institute, "Natural Gas Storage in Salt Caverns -Present Status, Developments and Future Trends in Europe", Technical Conference Paper, Basel, May 2007.

[17] Solution Mining Research Institute, "An overview of the Carriço Gas Storage Project Development", Technical Conference Paper, Porto, April 2008.

[18] Gas Infrastructure Europe, "Storage Map 2014". Available http://www.gie.eu/download/maps/2014/GSE_STOR_MAP_JULY201 4.pdf

[19] European Environment Agency (EEA), "Data and maps". Available http://www.eea.europa.eu/data-and-maps

[20] Kost et al.,"Levelized Cost of Electricity Renewable Energy Technologies", Study, Fraunhofer ISI (Freiburg), November 2013.

[21] The INGAA Foundation Inc., "Natural Gas Pipeline and Storage Infrastructure Projections Through 2030", ICF International, Washington, October 2009.

[22] ICF Consulting Ltd., "Unit Costs of constructing new transmission assets at $380 \mathrm{kV}$ within the European Union, Norway and Switzerland", Final Report, London, October 2002.

[23] X-rates.com, current and historical exchange rates $\$$ in $€$, accessed on July 22, 2014.

[24] INEGI and APREN, "Energias Endógenas de Portugal (Endogenous Energies of Portugal, e2p). Available http://e2p.inegi.up.pt/

[25] Entidade Reguladora dos Serviços Energéticos, "RELATÓRIO ANUAL PARA A COMISSÃO EUROPEIA 2013 PORTUGAL". Available

http://www.erse.pt/pt/uniaoeuropeia/Documents/Relat\%C3\%B3rio\%20 CE\%202013_PT.pdf, accessed on July 23, 2014.

[26] ERSE, "TARIFAS E PREÇOS DE GÁS NATURAL PARAO ANO GÁS 2010-2011 EPARÂMETROS PARA O PERÍODO DE REGULAÇÃO 2010-2013“, Final Report,Lisbon, July 2010. 